partita und Cassiodors - ohne jetzt von den so zahlreichen Anleihen in den byzantinischen Autoren zu sprechen - hat man fast immer das Mittel, die Überlieferung zu kontrollieren und zu unterscheiden, was selbst in den besten Handschriften Fehler oder Entstellung ist.

Unter diesen Umständen konnte nicht die Rede davon sein, daß zu dem bequemen System gegriffen würde, nur einer Überlieferung, wäre es auch die von B, mechanisch zu folgen. B allein z. B. gegen AnTCass. hat kaum Aussicht, das Richtige zu bieten; Lesarten von A oder An lassen sich als vortrefflich erweisen. Ebenso ist es mit Lesarten von $\mathbf{n}$ oder $r$, während solche von $r v$ fast immer dem Verdacht unterliegen, falsch zu sein, wie es der Stammbaum der Handschriften zeigt.

Es mußte also in jedem Fall eine kritische Wahl unter den Zeugnissen getroffen werden, deren Zahl, Wert und Gruppierung fortwährend wechseln, und diese Wahl hat im allgemeinen große Aussicht, uns dem Urtext Theodorets nahe zu bringen.

Man kann behaupten, daß der so gewonnene Text für die erzählenden Teile einen recht correcten Archetypus wiederherstellt. Die Frage gewinnt, wie sich zeigen wird, ein ganz anderes Aussehen, wenn es sich um die Urkunden handelt.

\title{
IX. Die Urkunden
}

Theodoret hat in seine Kirchengeschichte eine Menge von Urkunden eingeflochten - in runden Zahlen 139 Seiten auf 349 meiner Ausgabe und hat sich offenbar gerade durch dies Verfahren einen Vorzug gegenüber seinen Vorgängern sichern wollen. Darin hat er sich übrigens nicht getäuscht, denn heute machen für uns die Urkunden den Hauptwert seines Buches aus.

Einige Urkunden sind nur durch Theodoret auf uns gekommen, aber für die meisten besitzen wir gleichfalls eine Überlieferung bei andern griechischen Autoren oder selbst in der lateinischen Literatur.

Für die Aufstellung des Textes wird man in jedem Fall zu bestimmen suchen, welcher Quelle Theodoret seine Urkunde entlehnt hat. Ist etwa ein Actenstück, das ebenfalls bei Eusebins und Socrates vorkommt, aus einem dieser Autoren entnommen, oder ist es direct aus einer ähnlichen Sammlung entlehnt wie die, aus der es Eusebius und Socrates ihrerseits geschöpft haben? Es mußte also für die Aufstellung des Textes versucht werden, in jedem Fall festzustellen, ob die andern Autoren in der Eigenschaft als Quellen oder als Parallelzeugen in Betracht kommen. In dem Capitel über die Quellen lege 
ich die Schlußfolgerungen dar, die sich mir in dieser Hinsicht als die wahrscheinlichsten herausgestellt haben.

Dieselben Handschriften, die uns bei den Erzählungen in den Stand setzen, einen correcten Text aufzustellen, führen uns häufig, wenn es sich um Urkunden handelt, nur zu einem fehlerhaften und unerklärlichen Text. In manchen Fällen stand ein Fehler, selbst wenn er schon in der ersten Abschrift des Theodoret vorlag, nicht in dem Text, der copiert werden sollte. So haben z. B. 126, 13 die Worte $\varepsilon \dot{v} \vartheta \dot{v} \varsigma$ $\tau \varepsilon \mu \omega^{\prime} v$, die durch Athanasius und Socrates gesichert, von allen Handschriften und von der Tripartita ausgelassen werden, eine Spur ihres Vorhandenseins in der Vorlage des Theodoret selbst in den von den besten

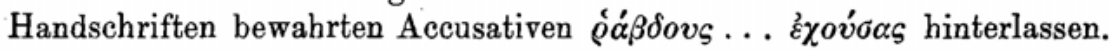
Aber im allgemeinen gehen die Fehler der Urkunden auf Theodorets eigene Quelle zurück und standen bereits in den Actenstücken, die er seinem Schreiber zum Copieren gab.

Einige Stellen, an denen sich Beispiele frur solche vor Theodoret liegenden Fehler finden, seien aufgezählt. Natürlich haben sie, wenn sie nicht von der Parallelüberlieferung so sicher bestätigt werden wie z. B. 40, 7. 149, 6/7, manchmal lediglich durch eine Nachlässigkeit des ersten Schreibers Theodorets entstehen können: 40, 7. 107, 13. 109, 4/5. 126,10 . 142,1 . 147,11 . $149,6 / 7$ u. 15 . 221,15 ff. 225,5 ff. 226,8 ff. $257,17.292,10$ usw.

Es läßt sich also behaupten, daß Theodoret schon in seinen Sammlungen Urkunden in schlechtem Zustand fand und daß mehrere derselben von Anfang an in ziemlich elender Weise aus dem Lateinischen übersetzt waren, besonders II 22; IV 8 und 9.

Ja die Vorstellung, die man sich von der Beschaffenheit dieser ursprünglichen Actenstücke bilden muß, läßt sich noch genauer bestimmen. Wenn man nämlich die Varianten der Urkunden mit der Parallelüberlieferung vergleicht, kommt man zuweilen zu dem Schluß, daß manche Doppellesarten sich bereits in der Quelle selbst fanden und von daher auf verschiedene Weise in die Abschriften gelangt sind. Ich habe in dieser Hinsicht bereits mehrere charakteristische Beispiele untersucht, so 148 , $2 \mathrm{ff}$ und 225, $11 \mathrm{ff}$ (s. oben S. XXVIII f, XXXIIIf und XL); vgl. auch 110, 10. 112, 19. 220, 12.

Stellt sich aber allen Schlußfolgerungen, welche den Text der Urkunden betreffen, nicht von vornherein ein Einwurf entgegen? Ist nämlich die theodoretische Überlieferung unabhängig geblieben und hat sie gar keine Beeinflussung durch die der Parallelautoren erfahren? Diese Frage ist für die Aufstellung des Textes von grundlegender Bedeutung und verdient eine besondere Prüfung. 